\title{
Axonal Transport and Local Translation of mRNA in Amyotrophic Lateral Sclerosis
}

\author{
Seiichi Nagano ${ }^{1,2} \bullet$ Toshiyuki Araki² \\ ${ }^{1}$ Department of Neurotherapeutics, Osaka University Graduate School of Medicine, Japan; \\ ${ }^{2}$ Department of Peripheral Nervous System Research, National Institute of Neuroscience, \\ National Center of Neurology and Psychiatry, Japan
}

Author for correspondence: Toshiyuki Araki, Department of Peripheral Nervous System Research, National Institute of Neuroscience, National Center of Neurology and Psychiatry, Japan. E-mail: taraki@ncnp.go.jp

Doi: https://doi.org/10.36255/exonpublications.amyotrophiclateralsclerosis.

axonaltransport.2021

\begin{abstract}
Since neurons have long neurites, especially axons, the transport of essential mRNAs, and their translation locally in axons, are essential to maintain the shape and function of the neurons. The RNA-binding protein TDP-43 (transactive response DNA binding protein 43) plays a crucial role in the transport and translation of mRNAs in neurons. In amyotrophic lateral sclerosis (ALS) and frontotemporal lobar degeneration (FTLD), TDP-43 and other RNA-binding proteins are mis-localized and abnormally deposited in neurons. Mutations of genes regulating these proteins have been identified in clinical cases. Impaired mRNA transport system may be a contributing factor of neurodegeneration in ALS/FTLD. In this chapter, we outline the role of RNA-binding proteins, with emphasis on TDP-43, in axonal transport and local translation of mRNAs in ALS/FTLD.
\end{abstract}

Keywords: amyotrophic lateral sclerosis; axonal transport; local translation; ribosomal protein; TDP-43

In: Amyotrophic Lateral Sclerosis. Araki T (Editor), Exon Publications, Brisbane, Australia. ISBN: 978-0-6450017-7-8. Doi: https://doi.org/10.36255/exonpublications. amyotrophiclateralsclerosis.2021

Copyright: The Authors.

License: This open access article is licenced under Creative Commons Attribution-NonCommercial 4.0 International (CC BY-NC 4.0) https://creativecommons.org/licenses/by-nc/4.0/ 


\section{INTRODUCTION}

Amyotrophic lateral sclerosis (ALS) is a neurodegenerative disease in which disorders of motor neurons cause paralysis and atrophy of muscles throughout the body. The disease has a poor prognosis and leads to a life-threatening state in 3-5 years mainly due to dysphagia or respiratory failure. To date, nearly 40 genes, including RNA-binding protein genes such as TARDBP (transactive response DNA binding protein), FUS (fused in sarcoma), and hnRNPA1 and hnRNPA2/B1 (heterogeneous nuclear ribonucleoproteins $\mathrm{Al}$ and $\mathrm{A} 2 / \mathrm{B} 1$ ), have been identified as contributing factors for ALS pathogenesis (1). TARDBP codes for TDP-43 (transactive response DNA binding protein $43 \mathrm{kDa}$ ). In addition, C9orf72 has been identified as the most frequent causative gene of familial ALS, in which abnormal expansion of a hexanucleotide repeat sequence (GGGGCC) in the noncoding region of the gene is observed (1). These gene mutations are responsible for tau-negative frontotemporal lobar degeneration (FTLD) and ALS, suggesting that these two diseases share a common pathological mechanism. In addition to familial cases caused by gene mutations, the disappearance of TDP-43 from the nucleus, and the aggregation/deposition of truncated, hyperphosphorylated, and ubiquitinated TDP-43 in the cytoplasm are observed in neurons of most sporadic ALS cases, which is one of the major pathological hallmarks of the disease $(2,3)$. In addition, abnormal cytoplasmic mis-localization/deposition of FUS, and the co-localization of other RNA-binding proteins with TDP-43 or FUS, have been reported $(4,5)$. These observations suggest that functional changes in RNAbinding proteins, including TDP-43 and FUS, occur in ALS neurons and that aberrant RNA metabolism caused by these changes may be involved in the pathogenesis of ALS.

\section{FUNCTION OF RNA-BINDING PROTEINS}

TDP-43 and FUS are expressed ubiquitously in the body, and they are mainly present in the nucleus of cells. Both TDP-43 and FUS control the transcription of genes and the splicing of transcribed immature pre-mRNAs (6). It is also reported that TDP-43 and FUS are involved in the regulation of miRNA biogenesis $(7,8)$. In addition, TDP-43 and FUS shuttle between the nucleus and cytoplasm, export mRNAs from the nucleus, transport mRNAs in the cytoplasm, and regulate their translation (6). mRNAs released from the nucleus exist in the form of mRNARNA-binding protein complexes, called RNA granules, within the cytoplasm. Each RNA-binding protein has a consensus motif of RNA sequence with highaffinity binding capabilities for specific mRNAs. mRNAs are transported to the required site with their translation suppressed by RNA-binding proteins in RNA granules. Subsequently, mRNAs are released from the granules for translation by ribosomes into proteins (9). There are different types of neuronal RNA granules, including stress granules, transport granules, and P bodies (processing bodies). Stress granules are formed during cellular stress, for example, starvation and oxidative stress. Transport granules transport mRNAs in axons and dendrites, and $\mathrm{P}$ bodies are involved in mRNA degradation (9). RNA-binding proteins interact 
and complex with each other to form RNA granules, and thus modulate the function of each other. For example, fragile X mental retardation protein (FMRP), the causative gene product of fragile X syndrome, has been reported to form a complex with TDP-43 which alters its aggregation activity and translation of target mRNAs (10).

Neurons have long neurites. Axons can be up to a meter long in motor neurons with an area 1,000 times that of their cell bodies. At the tip of axons, growth cones and pre-synapses exist in developing and mature neurons, respectively, which support binding with other neurons, or effector receptors, to form synapses and communicate with each other. To maintain the axonal morphology and function, neurons actively transport cell components such as proteins and intracellular organelles along axons via motor proteins, for example, kinesin superfamily proteins (11). Most of the proteins required for axonal formation and maintenance were previously thought to be supplied by transporting the translated proteins directly from the cell bodies. However, in recent years, there is growing evidence that a subset of mRNAs is transported along axons as neuronal RNA granules where translation of the proteins occurs locally, at destination. In axons, all the machinery necessary for local translation, such as ribosomes, translation initiation factors, and elongation factors are present (12) to take part in the protein supply locally. The transport and local translation of mRNAs in axons actively take place during axon pathfinding and outgrowth to the projection destination through neurogenesis, formation of networks via synapses, and regeneration of axons and synapses during neuronal injury. They also help to maintain axons in a mature, steady state (13). The advantage of local translation of mRNA in axons is that it can supply proteins more quickly upon demand than transporting proteins along the axons.

\section{PATHOLOGICAL ROLE OF RNA GRANULES}

TDP-43 and FUS are constituents of stress granules, which repress the translation of mRNAs (14). Both TDP-43 and FUS are also involved in axonal transport of mRNAs $(15,16)$. Both RNA-binding proteins have highly hydrophobic amino acid sequence regions called the low-complexity domains (LCD), through which they interact with each other to form multimers. This contributes to the formation of RNA granules with a non-membranous interface called liquid droplets. Mutations of the genes found in familial ALS reside mainly in the LCD of TDP-43, and the nuclear localization signal (NLS) site required for nuclear import of FUS. These mutations affect the intracellular localization as well as aggregation propensity of proteins. Mutant TDP-43 and FUS cause dysregulation of stress granules and trigger the formation and aggregation of inclusion bodies in ALS (14). Furthermore, mutations in TDP-43 increase granule viscosity, confer toxic gainof-function effects, and cause morphological instability of RNA granules leading to impaired anterograde axonal transport in $\operatorname{ALS}(15,17)$.

As impaired TDP-43 and FUS-mediated pathological conditions of ALS progress, the amount of proteins required for normal physiological transport of mRNAs for local translation in axons decrease. Furthermore, TDP-43 and FUS themselves, accumulated in the axons, inhibit their own function of axonal 
mRNA transport $(5,18)$. Consequently, reduced transport of critical mRNAs for axonal maintenance will cause morphological and functional changes of axons, ultimately resulting in degeneration of motor neurons. Functional deficits at neuromuscular junctions precede the clinical phenotype and motor neuron loss in mutant TDP-43 or wild-type FUS transgenic mice $(19,20)$. Studies in cultured motor neurons and zebrafish indicate that TDP-43 and FUS are involved in axon outgrowth (21-23). These findings imply that axonal degeneration is a primary executor of ALS pathogenesis. TDP-43 transports mRNAs of NEFL and futsch/ MAP1B in axons. Futsch/MAP1B regulates synaptic microtubule organization, and aberrant neuromuscular junctions are observed in TDP-43 mutant Drosophila due to a decrease of MAP1B mRNA and translated protein at synapses $(24,25)$. FUS transports mRNA of Fos-B in axons, dysregulation of which causes abnormal axon branching (26). It has also been shown that TDP-43 and FUS bind to mRNAs that have structures called G-quadruplex and transport them to neurites $(27,28)$. ALS-linked mutant TDP-43 lacks the activity of binding and transport of mRNAs bearing G-quadruplex, which correspond to approximately $30 \%$ of neuronal mRNAs (27). Thus, decreased levels of functional TDP-43 may cause reduced axonal mRNA transport and resultant axonal degeneration in ALS.

\section{RIBOSOMAL PROTEIN mRNAS AS AXONAL TRANSPORT TARGETS}

Ribosomes are involved in the translation of proteins from mRNAs, and there are two types in eukaryotes: cytoplasmic and mitochondrial. Each type is composed of about 80 different ribosomal proteins and four ribosomal RNAs. Ribosomes are present in axons as well as in cell bodies of neurons. mRNAs of translation-related proteins, including ribosomal proteins, are abundant in axons compared to those in cell bodies (29-31), suggesting that the transport of the mRNAs to axons has functional significance. Although some target mRNAs transported by TDP-43 in axons have been reported, there has been no comprehensive study to identify critical TDP-43 targets in relation to ALS pathogenesis. Therefore, we searched for transport target mRNAs of TDP-43 unbiasedly by using compartment culture devices to isolate axon-rich fractions (29). In our analysis, many cytoplasmic ribosomal protein (Rp) mRNAs were reduced in axons, but mitochondrial ribosomal protein mRNAs were not reduced. This means that the sequence specific to cytoplasmic ribosomal protein mRNAs may be important for axonal transport by TDP-43.

TDP-43 and Rp mRNAs are present in a granular pattern in axons, colocalize with each other and move along axons as one, reflecting that Rp mRNAs are transported by RNA granules containing TDP-43. The mRNAs of Rp and translation elongation factors have a unique pyrimidine repeat sequence called 5 'terminal oligopyrimidine (5'TOP) in their 5'untranslated regions, which is thought to be the binding site of TDP-43 for axonal transport. Among the RNA-binding proteins known to bind to mRNAs with 5'TOP is La, which was identified as an autoantigen in rheumatic diseases, and controls the translation of 5'TOP mRNAs by binding to them (32). La co-localizes with TDP-43 and Rp mRNAs in axons and 


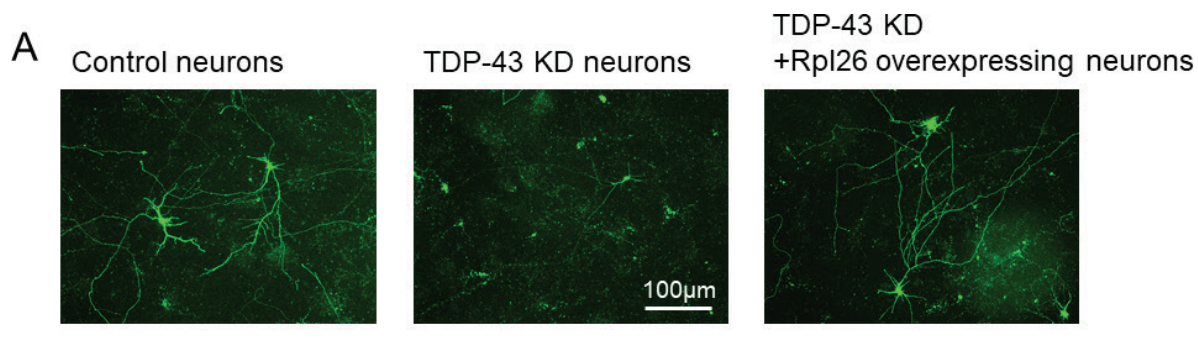

B

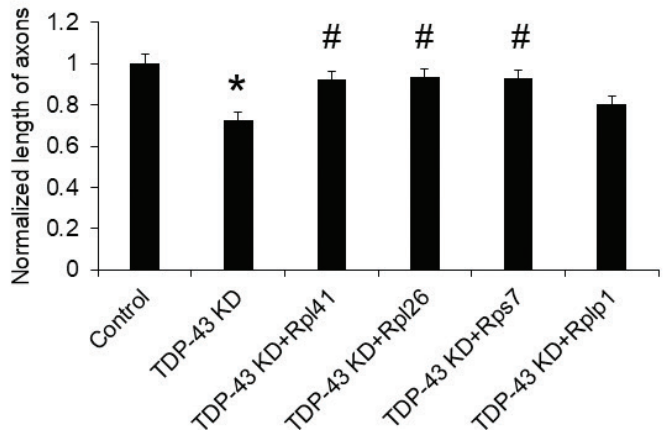

Figure 1. Rescue of axon outgrowth deficit in TDP-43-knockdown neurons by Rp overexpression. A. Representative images of neurons in each condition. B. Axon length in each group. Rpl41, Rpl26, Rps7 and Rplp1 were examined as representative Rp components. Results indicate mean \pm standard error. ${ }^{*} \mathrm{P}<0.001$ compared with control neurons, and $\# \mathrm{P}<0.005$ compared with TDP-43 KD neurons by one-way ANOVA test. KD, knockdown; Rp, cytoplasmic ribosomal protein.

binds to TDP-43. In ALS patients with pathological changes of TDP-43 localization, RP mRNAs are reduced in the pyramidal tracts of the medulla oblongata where the axons of motor neurons exist (29). Overexpression of several Rps mitigates the deficit of axon outgrowth caused by TDP-43 knockdown (Figure 1), suggesting that Rps may be useful tools for treating ALS and FTLD.

\section{LOCAL TRANSLATION IN AXONS IN PHYSIOLOGICAL}

\section{CONDITIONS AND ALS PATHOGENESIS}

Ribosome assembly occurs primarily in the nucleolus, and it has been thought that ribosomes present in axons are maintained after assembly by transport from cell bodies or supply from glial cells (33). However, in recent years, it has been reported that some Rps are replaced with newly translated ones on aged ribosomes existing in the cytoplasm (34), and Rp mRNAs are locally translated at axon terminals to maintain the function of ribosomes to aid in axonal branching (35). It is also known that mRNAs of the translation initiation factors eIF2B2 and eIF4G2 are transported in axons, where they are translated into proteins, and involved in 
the maintenance of overall local translation function (36). More recently, it has been pointed out that ribosomes have heterogeneity depending on the cell types and subcellular compartments and may have a translation function specific to each site (37). These observations indicate that proper functioning of ribosomes and translation factors are essential for maintaining local translation in axons, and the survival of neurons.

$\mathrm{Rp}$ and mitochondrial complex-related mRNAs are unstable in fibroblasts and induced pluripotent stem cells of C9orf72-mutated ALS patients (38). Also, TDP-43 has been shown to regulate local translation in axons of motor neurons (39). Furthermore, mice expressing mutant FUS have an overall decrease of local translation in axons (16). These findings strongly suggest that Rp mRNA metabolism disorders or ribosome dysfunction may be involved in the pathogenesis of ALS. Therefore, we hypothesize that Rp mRNAs transported in axons by TDP-43 regulate translation function of axonal ribosomes by replacing defective Rps with locally translated ones, the disturbance of which will cause neurodegeneration in ALS and FTLD (Figure 2).

The importance of local translation in motor axons has been demonstrated in another motor neuron disease, spinal muscular atrophy (SMA). SMA is caused by a decrease in the survival motor neuron (SMN) protein due to deletions or mutations of the gene SMN1. Although SMN has no evidence of direct binding to mRNA, it is supposed to control transport and local translation of mRNA in axons through binding to RNA-binding proteins (40). SMN protein controls axon growth by modulating localization of $\beta$-actin mRNA in growth cones (41). Recent reports indicate that SMN protein regulates local translation in axons via axonal transport of the cytoskeletal-related protein growth-associated protein 43 (GAP43) mRNA (40). Furthermore, it has been reported that a decrease in SMN protein reduces the translation of $m$ Tor, which is a key molecule for protein translation by increasing the expression of miR-183 in axons and suppressing local translation (42). These findings indicate that maintenance of local axon translation function is particularly important for motor neuron survival, and that its breakdown is involved in motor neuron degeneration.

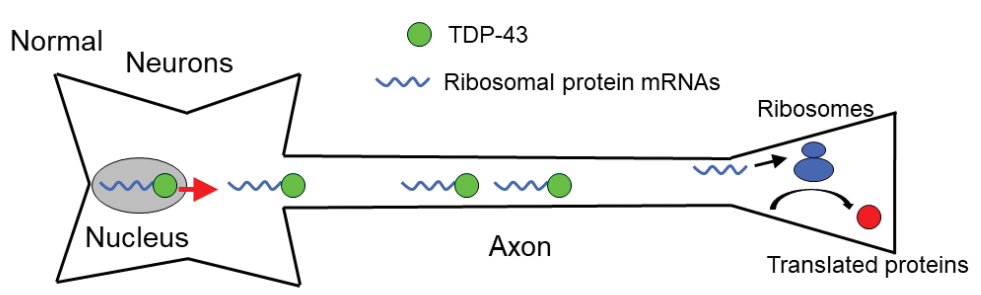

ALS/FTLD

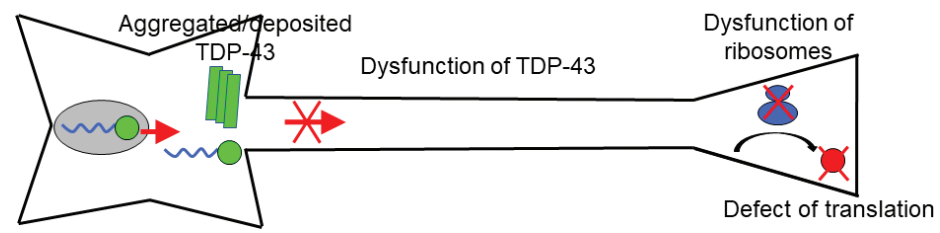

Figure 2. Schematic representation of ALS/FTLD pathogenesis due to defective local translation in axons. 


\section{CONCLUSION}

In the future, functional analyses of other ALS-causing gene mutations and further analyses using ALS patient samples will clarify the significance of local translational dysfunction in neuronal axons in the pathogenesis of ALS. Furthermore, by identifying the most critical proteins involved in neurodegeneration due to the local translation deficit, new therapeutic targets could be identified.

Conflict of interest: The authors declare no potential conflicts of interest with respect to research, authorship and/or publication of this manuscript.

Copyright and permission statement: The authors confirm that the materials included in this chapter do not violate copyright laws. Where relevant, appropriate permissions have been obtained from the original copyright holder(s), and all original sources have been appropriately acknowledged or referenced.

\section{REFERENCES}

1. Mejzini R, Flynn LL, Pitout IL, Fletcher S, Wilton SD, Akkari PA. ALS genetics, mechanisms, and therapeutics: Where are we now? Front Neurosci. 2019;13:1310. https://doi.org/10.3389/ fnins.2019.01310

2. Arai T, Hasegawa M, Akiyama H, Ikeda K, Nonaka T, Mori H, et al. TDP-43 is a component of ubiquitin-positive tau-negative inclusions in frontotemporal lobar degeneration and amyotrophic lateral sclerosis. Biochem Biophys Res Commun. 2006;351(3):602-11. https://doi.org/10.1016/j. bbrc.2006.10.093

3. Neumann M, Sampathu DM, Kwong LK, Truax AC, Micsenyi MC, Chou TT, et al. Ubiquitinated TDP-43 in frontotemporal lobar degeneration and amyotrophic lateral sclerosis. Science. 2006;314(5796):130-3. https://doi.org/10.1126/science.1134108

4. Kattuah W, Rogelj B, King A, Shaw CE, Hortobágyi T, Troakes C. Heterogeneous nuclear ribonucleoprotein E2 (hnRNP E2) is a component of TDP-43 aggregates specifically in the A and C pathological subtypes of frontotemporal lobar degeneration. Front Neurosci. 2019;13:551. https://doi.org/10.3389/ fnins.2019.00551

5. Gami-Patel P, Bandopadhyay R, Brelstaff J, Revesz T, Lashley T. The presence of heterogeneous nuclear ribonucleoproteins in frontotemporal lobar degeneration with FUS-positive inclusions. Neurobiol Aging. 2016;46:192-203. https://doi.org/10.1016/j.neurobiolaging.2016.07.004

6. Ederle H, Dormann D. TDP-43 and FUS en route from the nucleus to the cytoplasm. FEBS Lett. 2017;591(11):1489-1507. https://doi.org/10.1002/1873-3468.12646

7. Kawahara Y, Mieda-Sato A. TDP-43 promotes microRNA biogenesis as a component of the Drosha and Dicer complexes. Proc Natl Acad Sci U S A. 2012;109(9):3347-52. https://doi.org/10.1073/ pnas. 1112427109

8. Morlando M, Dini Modigliani S, Torrelli G, Rosa A, Di Carlo V, Caffarelli E, et al. FUS stimulates microRNA biogenesis by facilitating co-transcriptional Drosha recruitment. EMBO J. 2012;31(24): 4502-10. https://doi.org/10.1038/emboj.2012.319

9. Anderson P, Kedersha N. RNA granules: post-transcriptional and epigenetic modulators of gene expression. Nat Rev Mol Cell Biol. 2009;10(6):430-6. https://doi.org/10.1038/nrm2694

10. Coyne AN, Yamada SB, Siddegowda BB, Estes PS, Zaepfel BL, Johannesmeyer JS, et al. Fragile X protein mitigates TDP-43 toxicity by remodeling RNA granules and restoring translation. Hum Mol Genet. 2015;24(24):6886-98. https://doi.org/10.1093/hmg/ddv389

11. Hirokawa N, Noda Y, Tanaka Y, Niwa S. Kinesin superfamily motor proteins and intracellular transport. Nat Rev Mol Cell Biol. 2009;10(10):682-96. https://doi.org/10.1038/nrm2774 
12. Holt CE, Martin KC, Schuman EM. Local translation in neurons: visualization and function. Nat Struct Mol Biol. 2019;26(7):557-566. https://doi.org/10.1038/s41594-019-0263-5

13. Twiss JL, Kalinski AL, Sachdeva R, Houle JD. Intra-axonal protein synthesis - a new target for neural repair? Neural Regen Res. 2016 Sep;11(9):1365-1367. https://doi.org/10.4103/1673-5374.191193

14. Aulas A, Vande Velde C. Alterations in stress granule dynamics driven by TDP-43 and FUS: a link to pathological inclusions in ALS? Front Cell Neurosci. 2015;9:423. https://doi.org/10.3389/fncel. 2015.00423

15. Alami NH, Smith RB, Carrasco MA, Williams LA, Winborn CS, Han SSW, et al. Axonal transport of TDP-43 mRNA granules is impaired by ALS-causing mutations. Neuron. 2014;81(3):536-543. https://doi.org/10.1016/j.neuron.2013.12.018

16. López-Erauskin J, Tadokoro T, Baughn MW, Myers B, McAlonis-Downes M, Chillon-Marinas C, et al. ALS/FTD-linked mutation in FUS suppresses intra-axonal protein synthesis and drives disease without nuclear loss-of-function of FUS. Neuron. 2018;100(4):816-830. https://doi.org/10.1016/j. neuron.2018.09.044

17. Gopal PP, Nirschl JJ, Klinman E, Holzbaur EL. Amyotrophic lateral sclerosis-linked mutations increase the viscosity of liquid-like TDP-43 RNP granules in neurons. Proc Natl Acad Sci U S A. 2017;114(12):E2466-E2475. https://doi.org/10.1073/pnas.1614462114

18. Braak H, Ludolph A, Thal DR, Del Tredici K. Amyotrophic lateral sclerosis: dash-like accumulation of phosphorylated TDP-43 in somatodendritic and axonal compartments of somatomotor neurons of the lower brainstem and spinal cord. Acta Neuropathol. 2010;120(1):67-74. https://doi.org/10.1007/ s00401-010-0683-0

19. Chand KK, Lee KM, Lee JD, Qiu H, Willis EF, Lavidis NA, et al. Defects in synaptic transmission at the neuromuscular junction precede motor deficits in a TDP-43Q331 K transgenic mouse model of amyotrophic lateral sclerosis. FASEB J. 2018;32(5):2676-2689. https://doi.org/10.1096/fj.201700835R

20. So E, Mitchell JC, Memmi C, Chennell G, Vizcay-Barrena G, Allison L, et al. Mitochondrial abnormalities and disruption of the neuromuscular junction precede the clinical phenotype and motor neuron loss in hFUSWT transgenic mice. Hum Mol Genet. 2018;27(3):463-474. https://doi.org/10.1093/ hmg/ddx415

21. Fallini C, Bassell GJ, Rossoll W. The ALS disease protein TDP-43 is actively transported in motor neuron axons and regulates axon outgrowth. Hum Mol Genet. 2012;21(16):3703-18. https://doi. org/10.1093/hmg/dds205

22. Schmid B, Hruscha A, Hogl S, Banzhaf-Strathmann J, Strecker K, van der Zee J, et al. Loss of ALSassociated TDP-43 in zebrafish causes muscle degeneration, vascular dysfunction, and reduced motor neuron axon outgrowth. Proc Natl Acad Sci U S A. 2013;110(13):4986-91. https://doi.org/10.1073/ pnas. 1218311110

23. Kabashi E, Bercier V, Lissouba A, Liao M, Brustein E, Rouleau GA, et al. FUS and TARDBP but not SOD1 interact in genetic models of amyotrophic lateral sclerosis. PLoS Genet. 2011;7(8):e1002214. https://doi.org/10.1371/journal.pgen.1002214

24. Godena VK, Romano G, Romano M, Appocher C, Klima R, Buratti E, et al. TDP-43 regulates Drosophila neuromuscular junctions growth by modulating Futsch/MAP1B levels and synaptic microtubules organization. PLoS One. 2011;6(3):e17808. https://doi.org/10.1371/journal.pone.0017808

25. Coyne AN, Siddegowda BB, Estes PS, Johannesmeyer J, Kovalik T, Daniel SG, et al. Futsch/MAP1B mRNA is a translational target of TDP-43 and is neuroprotective in a Drosophila model of amyotrophic lateral sclerosis. J Neurosci. 2014;34(48):15962-74. https://doi.org/10.1523/JNEUROSCI. 2526-14.2014

26. Akiyama T, Suzuki N, Ishikawa M, Fujimori K, Sone T, Kawada J, et al. Aberrant axon branching via Fos-B dysregulation in FUS-ALS motor neurons. EBioMedicine. 2019;45:362-378. https://doi. org/10.1016/j.ebiom.2019.06.013

27. Ishiguro A, Kimura N, Watanabe Y, Watanabe S, Ishihama A. TDP-43 binds and transports G-quadruplex-containing mRNAs into neurites for local translation. Genes Cells. 2016;21(5):466-81. https://doi.org/10.1111/gtc. 12352 
28. Imperatore JA, McAninch DS, Valdez-Sinon AN, Bassell GJ, Mihailescu MR. FUS recognizes G quadruplex structures within neuronal mRNAs. Front Mol Biosci. 2020;7:6. https://doi.org/10.3389/ fmolb.2020.00006

29. Nagano S, Jinno J, Abdelhamid RF, Jin Y, Shibata M, Watanabe S, et al. TDP-43 transports ribosomal protein mRNA to regulate axonal local translation in neuronal axons. Acta Neuropathol. 2020;140(5):695-713. https://doi.org/10.1007/s00401-020-02205-y

30. Bigler RL, Kamande JW, Dumitru R, Niedringhaus M, Taylor AM. Messenger RNAs localized to distal projections of human stem cell derived neurons. Sci Rep. 2017;7(1):611. https://doi.org/10.1038/ s41598-017-00676-w

31. Rotem N, Magen I, Ionescu A, Gershoni-Emek N, Altman T, Costa CJ, et al. ALS along the axons Expression of coding and noncoding RNA differs in axons of ALS models. Sci Rep. 2017;7:44500. https://doi.org/10.1038/srep44500

32. Crosio C, Boyl PP, Loreni F, Pierandrei-Amaldi P, Amaldi F. La protein has a positive effect on the translation of TOP mRNAs in vivo. Nucleic Acids Res. 2000;28(15):2927-34. https://doi.org/10.1093/ nar/28.15.2927

33. Court FA, Hendriks WT, MacGillavry HD, Alvarez J, van Minnen J. Schwann cell to axon transfer of ribosomes: toward a novel understanding of the role of glia in the nervous system. J Neurosci. 2008;28(43):11024-9. https://doi.org/10.1523/JNEUROSCI.2429-08.2008

34. Pulk A, Liiv A, Peil L, Maiväli U, Nierhaus K, RemmeJ. Ribosome reactivation by replacement of damaged proteins. Mol Microbiol. 2010;75(4):801-14. https://doi.org/10.111l/j.1365-2958.2009.07002.x

35. Shigeoka T, Koppers M, Wong HH, Lin JQ, Cagnetta R, Dwivedy A, et al. On-site ribosome remodeling by locally synthesized ribosomal proteins in axons. Cell Rep. 2019;29(11):3605-3619. https:// doi.org/10.1016/j.celrep.2019.11.025

36. Kar AN, MacGibeny MA, Gervasi NM, Gioio AE, Kaplan BB. Intra-axonal synthesis of eukaryotic translation initiation factors regulates local protein synthesis and axon growth in rat sympathetic neurons. J Neurosci. 2013;33(17):7165-74. https://doi.org/10.1523/JNEUROSCI.2040-12.2013

37. Genuth NR, Barna M. The discovery of ribosome heterogeneity and its implications for gene regulation and organismal life. Mol Cell. 2018;71(3):364-374. https://doi.org/10.1016/j.molcel.2018.07.018

38. Tank EM, Figueroa-Romero C, Hinder LM, Bedi K, Archbold HC, Li X, et al. Abnormal RNA stability in amyotrophic lateral sclerosis. Nat Commun. 2018;9(1):2845. https://doi.org/10.1038/ s41467-018-05049-z

39. Briese M, Saal-Bauernschubert L, Lüningschrör P, Moradi M, Dombert B, Surrey V, et al. Loss of Tdp-43 disrupts the axonal transcriptome of motoneurons accompanied by impaired axonal translation and mitochondria function. Acta Neuropathol Commun. 2020;8(1):116. https://doi.org/10.1186/ s40478-020-00987-6

40. Fallini C, Donlin-Asp PG, Rouanet JP, Bassell GJ, Rossoll W. Deficiency of the survival of motor neuron protein impairs mRNA localization and local translation in the growth cone of motor neurons. J Neurosci. 2016;36(13):3811-20. https://doi.org/10.1523/JNEUROSCI.2396-15.2016

41. Rossoll W, Jablonka S, Andreassi C, Kröning AK, Karle K, Monani UR, et al. Smn, the spinal muscular atrophy-determining gene product, modulates axon growth and localization of beta-actin mRNA in growth cones of motoneurons. J Cell Biol. 2003;163(4):801-12. https://doi.org/10.1083/ jcb. 200304128

42. Kye MJ, Niederst ED, Wertz MH, Gonçalves Ido C, Akten B, Dover KZ, et al. SMN regulates axonal local translation via miR-183/mTOR pathway. Hum Mol Genet. 2014;23(23):6318-31. https://doi. org/10.1093/hmg/ddu350 
